\title{
A LCIAPCI-MS/MS Method for Analysis of Imidacloprid in Soils, in Plants, and in Pollens
}

\author{
J. M. Bonmatin, ${ }^{*},{ }^{\dagger}$ I. Moineau, ${ }^{\dagger}$ R. Charvet, ${ }^{\dagger}$ C. Fleche, ${ }^{\ddagger}$ M. E. Colin,${ }^{\S}$ and E. R. Bengsch ${ }^{\dagger}$ \\ Centre de Biophysique Moleculaire, CNRS and Universite Orleans, 45071 Orleans Cedex 02, France, \\ Laboratoire de Pathologie des Petits Ruminants et des Abeilles, AFSSA, 06902 Sophia Antipolis Cedex, France, and \\ INRA-UAPV Ecologie des invertébrés, 84914 Avignon Cedex 09, France
}

Imidacloprid, the most used systemic insecticide, is suspected of having harmful effects on honeybees at nanogram per bee or at microgram per kilogram levels. However, there is a lack of methodology to detect imidacloprid and its metabolites at such low levels. We developed a method for the determination of low amounts of imidacloprid in soils, plants (leaves and flowers), and pollens by using HPLC coupled to tandem mass spectrometry (APCI-MS/MS). Extraction, separation, and detection were performed according to quality assurance criteria, to Good Laboratory Practice, and to criteria from the directive 96/23/ EC, which is designed for banned substances. The linear range of application is $0.5-20 \mu \mathrm{g} /$ kg imidacloprid in soils, in plants, and in pollens, with a relative standard deviation of $2.9 \%$ at $1 \mu \mathrm{g} / \mathrm{kg}$. The limits of detection and of quantification are LOD $=0.1 \mu \mathrm{g} / \mathrm{kg}$ and $L O Q=1 \mu \mathrm{g} / \mathrm{kg}$, respectively. For the first time, this study permitted us to follow the fate of imidacloprid in the environment. When treated, flowers of sunflower and maize contain average values of $\sim 10 \mu \mathrm{g} / \mathrm{kg}$ imidacloprid. This explains that pollens from these crops are contaminated at levels of a few micrograms per kilogram, suggesting probable deleterious effects on honeybees.

Imidacloprid, 1-(6 chloronicotinyl)-2-(nitroimino)imidazolidine, is a relatively new insecticide with high activity against sucking insects. ${ }^{1}$ It is the most used systemic insecticide in the world ( $\sim 70$ crops in more than 100 countries). It is systemic when used as seed dressing or soil treatment because it is distributed in plants by the sap. Imidacloprid works by interfering with the transmission of stimuli in the insect's nervous system. It causes a blockage in at least one type of nicotinergic neuronal pathway that is more abundant in insects than in warm-blooded animals. This makes imidacloprid much more toxic to insects than to other species. Furthermore, imidacloprid has a highly specific affinity to insect nicotinic acetylcholine receptors (nAChR).$^{2-5}$ Its binding leads to

\footnotetext{
* Corresponding author. E-mail: bonmatin@ cnrs-orleans.fr.

† CNRS and Université Orléans.

* AFSSA.

§ INRA-UAPV Ecologie des invertébrés.

(1) Moriya, K.; Shibuya, K.; Hattori, J.; Tsuboi, S.; Shiokawa, K.; Kagabu, S. Biosci. Biotechnol. Biochem. 1992, 56-2, 364-365.

(2) Bai, D.; Lummis, S. C. R.; Leicht, W.; Breer, H.; Sattelle, D. B. Pestic. Sci. $1991,33,197-204$.

(3) Liu, M.-Y. B.; Casida, E. Pestic. Biochem. Physiol. 1993, 46, 40-46.
}

the accumulation of acetylcholine, resulting in the paralysis and death of insects. ${ }^{2,3,6}$

The seed dressing for sunflower with imidacloprid was launched on the French market in 1994. Since 1995, beekeepers have observed the death of numerous bees and a drastic decrease in honey production. This problem has worsened with the increasing use of imidacloprid (formulation Gaucho) on sunflower and on others crops, such as maize and wheat. From this, imidacloprid has been suspected as having harmful effects on honeybees and large-scale studies were launched in France in 1998. Especially, the possible intoxication of bees could be due to the presence of imidacloprid in the pollen of treated crops. First, contaminated pollen would induce sublethal or chronic toxicity at the time of flowering. Second, contaminated pollen could be responsible for delayed intoxication since it is stocked as nutrient reserves in beehives.

Imidacloprid exhibits a high oral toxicity to bees. Depending on acute toxicity tests, the oral $50 \%$ lethal dose (LD50) was reported to be between 49 and $102 \mathrm{ng} /$ bee, ${ }^{7} 40$ and $60 \mathrm{ng} / \mathrm{bee},{ }^{8}$ at $5 \mathrm{ng} / \mathrm{bee},{ }^{9}$ and between 3.7 and $40.9 \mathrm{ng} /$ bee. ${ }^{10}$ The latter value corresponds to a lethal food contamination level of $100 \mu \mathrm{g} / \mathrm{kg} .{ }^{10}$ By contact, the LD50 was found at $24 \mathrm{ng} /$ bee after 24 and $48 \mathrm{~h}^{8}$ Note that the body weight of a bee is $\sim 100 \mathrm{mg}$. However, new studies have shown that the crucial functions of bees, such as foraging, are affected by sublethal contamination of food in the microgram per kilogram range ${ }^{11}$ Moreover, the chronic toxicity appears at an order of magnitude lower (50\% mortality at $0,1 \mu \mathrm{g} /$ $\mathrm{kg}$ after 8 days of exposure), not only for imidacloprid itself but also for most of its metabolites. ${ }^{12-14}$

For a comprehensive approach to the fate of imidacloprid in the environment, a quantitative method is needed in the analysis

(4) Leicht, W. Pestic. Outlook 1993, 4, 17-21.

(5) Yamamoto, I.; Yabuta, G.; Tomizawa, M.; Saito, T.; Miyamamoto, T.; Kagabu, S. J. Pestic. Sci. 1995, 20, 33-40.

(6) Buckingham, S.; Lapied, B.; Corronc, H.; Grolleau F.; Sattelle, D. B. J. Exp. Biol. 1997, 200, 2685-2692.

(7) Nauen, R.; Ebbinghaus-Kintscher, U.; Schmuck, R. Pestic. Manage. Sci. $2001,57,577-586$.

(8) Suchail, S.; Guez D.; Belzunces, L. P. Environ. Toxicol. Chem. 2001, 20 $2482-2486$

(9) Suchail, S.; Guez, D.; Belzunces, L. P. Environ. Toxicol. Chem. 2000, 19, 1901-1905.

(10) Schmuck, R.; Schöning, R.; Stork, A.; Schramel, O. Pestic. Manage. Sci. $2001,57,225-238$.

(11) Colin, M. E.; Bonmatin, J.-M. Effets de très faibles concentrations d'imidaclopride et dérivés sur le butinage des abeilles en conditions semi-contrôlées. Rapport 1 au Ministère de l'agriculture et de la pêche, 2000. 
of soils, plants, flowers, and pollens from field samples. Because the sublethal effects occur in the microgram per kilogram range, the method must detect imidacloprid at less than $1 \mu \mathrm{g} / \mathrm{kg}$. However, the analytical method available could not detect imidacloprid under $20-50 \mu \mathrm{g} / \mathrm{kg}$ in plants. ${ }^{15}$ Furthermore, pollens had never been analyzed.

Several methods have been reported for the analysis of imidacloprid. Although imidacloprid residues can be analyzed by derivatization and gas chromatography, ${ }^{16,17}$ high-performance liquid chromatography (HPLC) has been already used and appears to be a suitable alternative because of the thermolability and polarity of imidacloprid. Hence, the LC method gave good results for imidacloprid in groundwater, ${ }^{18}$ soils, ${ }^{19,20}$ and fruits and vegetables, ${ }^{21-23}$ but the limit of detection (LOD) was still too high for the present purpose. Furthermore, the required method must satisfy strict quality criteria to be classified as a confirmatory method. We developed a new extraction scheme with high recovery rates, coupled to a LC/ MS/ MS methodology in order to detect and quantify imidacloprid in soils, plants, flowers, and pollens, with fully valid procedures. Applications revealed the fate of imidacloprid in soils over 1 and 2 years. The distribution of imidacloprid in sunflowers has been depicted depending on the stage of growth and as a function of the plant variety. During the full flowering period, flowers contain on the order of $10 \mu \mathrm{g} / \mathrm{kg}$ imidacloprid in the cases of sunflower and maize. Contamination of these pollens was found at the level of a few micrograms per kilogram. More generally, such a method can be easily adapted for the analysis of fruits and vegetables.

\section{EXPERIMENTAL SECTION}

Chemicals, Reagents, and Starting Materials. HPLC grade solvents were used. Imidacloprid standard (purity 99.4\%, $\mathrm{C}_{9} \mathrm{H}_{10^{-}}$ $\mathrm{ClN}_{5} \mathrm{O}_{2}$ molecular mass $255.7 \mathrm{~g} / \mathrm{mol}$ (Figure 1a)) was supplied from Bayer AG (Leverkusen, Germany). Antipyrine (purity $>99 \%$ ) was used as an external standard and was purchased from Sigma Chemical Co. (St. Quentin Fallavier, France). Standard solutions were prepared in acetonitrile for imidacloprid, and in methanol for antipyrine. These standards (imidacloprid: 0.1 and $1 \mathrm{ng} / \mu \mathrm{L}$ ) were stored at $4{ }^{\circ} \mathrm{C}$ in the dark, where they are stable for several

(12) Belzunces, L. P.; Tasei, J.-N. Impacts sur les dépeuplements de colonies d'abeilles et sur les miellées. Rapport au Ministère de l'agriculture sur les effets des traitements de semences de tournesol au Gaucho (imidacloprid), 1997.

(13) Suchail, S.; Guez, D.; Belzunces, L. P. Toxicity of imidacloprid in Apis mellifera. In Hazards of Pesticides to Bees; INRA: Paris, 2000; pp 135-140.

(14) Guez, D.; Suchail, S.; Gauthier, M.; Maleszka, R.; Belzunces, L. P. Neurobiol. Learn. Mem. 2001, 76, 183-191.

(15) Placke, F. J.; Weber, E. , Pflanzenschutz-Nachr. Bayer 1993, 46 109-182.

(16) MacDonald, L.; Meyer, T. J. Agric. Food Chem. 1998, 46, 3133-3138.

(17) Uroz, F. J.; Arrebola, F. J.; Egea-Gonzales, F. J.; Martinez-Vidal, J. L. Analyst $2001,126,1355-1358$.

(18) Martinez-Galera, M.; Garrido-Frenich, A.; Martinez-Vidal, J. L.; ParrillaVasquez, P. J. Chromatogr., A 1998, 799, 149-154.

(19) Baskaran, K.; Kookana, R. S.; Naidu, R. J. J. Chromatogr., A 1997, 787, 271-275.

(20) Ruiz de Erenchun, N.; Gomez de Balugera, Z.; Aranzazu Goicolea, M.; Barrio, R. Anal. Chim. Acta 1997, 349, 199-206.

(21) Ishii, Y.; Kobori, I.; Araki, Y.; Kurogochi, S.; Iwaya, K.; Kagabu, S. J. Agric. Food Chem. 1994, 42, 2917-2921.

(22) Fernandez-Alba, R. A.; Valverde, A.; Agüera, A.; Contreras, M.; Chiron, S. J. Chromatogr., A 1996, 721, 97-105.

(23) Pous, X.; Ruiz, M.; Pico, Y.; Font, G. Fresenius J. Anal. Chem. 2001 , 371$7,182-189$ weeks. Calibration solutions were prepared from these standard solutions in a 50/50 (v/ v) mixture of acetonitrile/ $\mathrm{H}_{2} \mathrm{O}$.

To prepare a $\mathrm{pH} 7$ buffer, $42.4 \mathrm{~g}$ of sodium carbonate was dissolved in $900 \mathrm{~mL}$ of water and $30.5 \mathrm{~mL}$ of concentrated acetic acid was added while shaking. The solution was adjusted to 1000 $\mathrm{mL}$ with water. Solid-phase extraction was performed using an Isolut $50 \mathrm{mg}$ of $\mathrm{MFC}_{18}-3 \mathrm{~mL}$ (IST).

Pollen from mountain flowers (ciste) and from organically farmed areas were purchased from Percie du Sert (Saint-Hilaire de Lusignan, France). Other pollens of organically farmed crops were sampled directly from several areas in France. Plants and soils were sampled from numerous sites all over France. Plants were sampled at different stages of growth, these stages being defined according to a specific classification. ${ }^{24}$ Treated samples were compared to (i) organically farmed samples and to (ii) samples without imidacloprid treatment for 3 years or more. All samples were conserved at $-24^{\circ} \mathrm{C}$ in the dark and homogenized before analysis. Because organically farmed samples did not reveal any signal, they were used as control samples. Such samples demonstrated unambiguously that the sampling procedure was performed without any external contamination.

Sample Treatment. (1) Soils. Air-dried soils (20 g) were extracted by mixing with $100 \mathrm{~mL}$ of methanol/ $\mathrm{NH}_{4} \mathrm{OH} 0.05 \%$ (3/ 1) for $1 \mathrm{~min}$. Two grams of Celite was added. The mixture was vacuum filtered with methanol on a glass frit containing $2 \mathrm{~g}$ of wet Celite. The extract was dried by evaporating with a rotary evaporator at $50{ }^{\circ} \mathrm{C}$. The flask was rinsed out with $15 \mathrm{~mL}$ of dichloromethane. The extract was evaporated on a hot sand-bath. The residue was dissolved by using ultrasonication in $1 \mathrm{~mL}$ of $\mathrm{ACN} / \mathrm{H}_{2} \mathrm{O}$ (50/50) in sealed tubes. The extract was centrifuged at $10000 \mathrm{rpm}$ in 1.5-mL Eppendorf tubes for $2 \mathrm{~min}$. A total of 25 $\mu \mathrm{L}$ was injected in HPLC.

(2) Plants and Flowers. Plants (10 g) were extracted by grinding with $100 \mathrm{~mL}$ of methanol/ $\mathrm{H}_{2} \mathrm{SO}_{4} 0.04 \%$ (4/ 1) for $1 \mathrm{~min}$. Two grams of Celite was added, and the mixture was vacuum filtered on the glass frit containing $2 \mathrm{~g}$ of wet Celite. The extract was concentrated to $5-10 \mathrm{~mL}$ of water by evaporating with a rotary evaporator, at $60{ }^{\circ} \mathrm{C}$ maximum. The residue was made up to 15 $\mathrm{mL}$ with water and centrifuged (4000 rpm) for $5 \mathrm{~min}$. A $\mathrm{C}_{18}$ cartridge was preconditioned with $5 \mathrm{~mL}$ of methanol and $5 \mathrm{~mL}$ of water. The aqueous surnatant was transferred to the $\mathrm{C}_{18}$ cartridge. Then, the cartridge was rinsed with $5 \mathrm{~mL}$ of water and dried under vacuum. The extract was eluted with $5 \mathrm{~mL}$ of dichloromethane, and the eluate was collected. The residual aqueous phase, still present in the eluate, was taken out. The eluate was partially evaporated on a warm sand bath. The organic remainder was diluted with $1 \mathrm{~mL}$ of $\mathrm{ACN} / \mathrm{H}_{2} \mathrm{O}$ (50/50) containing $200 \mathrm{ng} / \mathrm{mL}$ antipyrine. The residue was centrifuged ( $4000 \mathrm{rpm}$ ) for $5 \mathrm{~min}$. A total of $20 \mu \mathrm{L}$ was injected in HPLC.

(3) Pollens. Pollens ( $10 \mathrm{~g}$ ) were put in $20 \mathrm{~mL}$ of $\mathrm{EtOH} / \mathrm{H}_{2} \mathrm{O}$ (75/25) and mixed in an Ultra-Turax blender T25 (Janke \& Kunkel) for $1 \mathrm{~min}$. The stem was rinsed 3 times with $5 \mathrm{~mL}$ of EtOH/ $\mathrm{H}_{2} \mathrm{O}$ (75/25). The extract was centrifuged (3600 rpm) for 5 min. This extraction was made twice. The extracted phases were recovered in a flask. The mixture was evaporated with a rotary evaporator to a final volume of $5 \mathrm{~mL}$ of water. Ten milliliters of the $\mathrm{pH} 7$ buffer $\left(\mathrm{Na}_{2} \mathrm{CO}_{3} / \mathrm{CH}_{3} \mathrm{COOH}\right)$ was added, and the mixture

(24) Lancashire, P. D.; Bleiholder, H. Ann. Appl. Biol. 1991, 119, 561-601. 

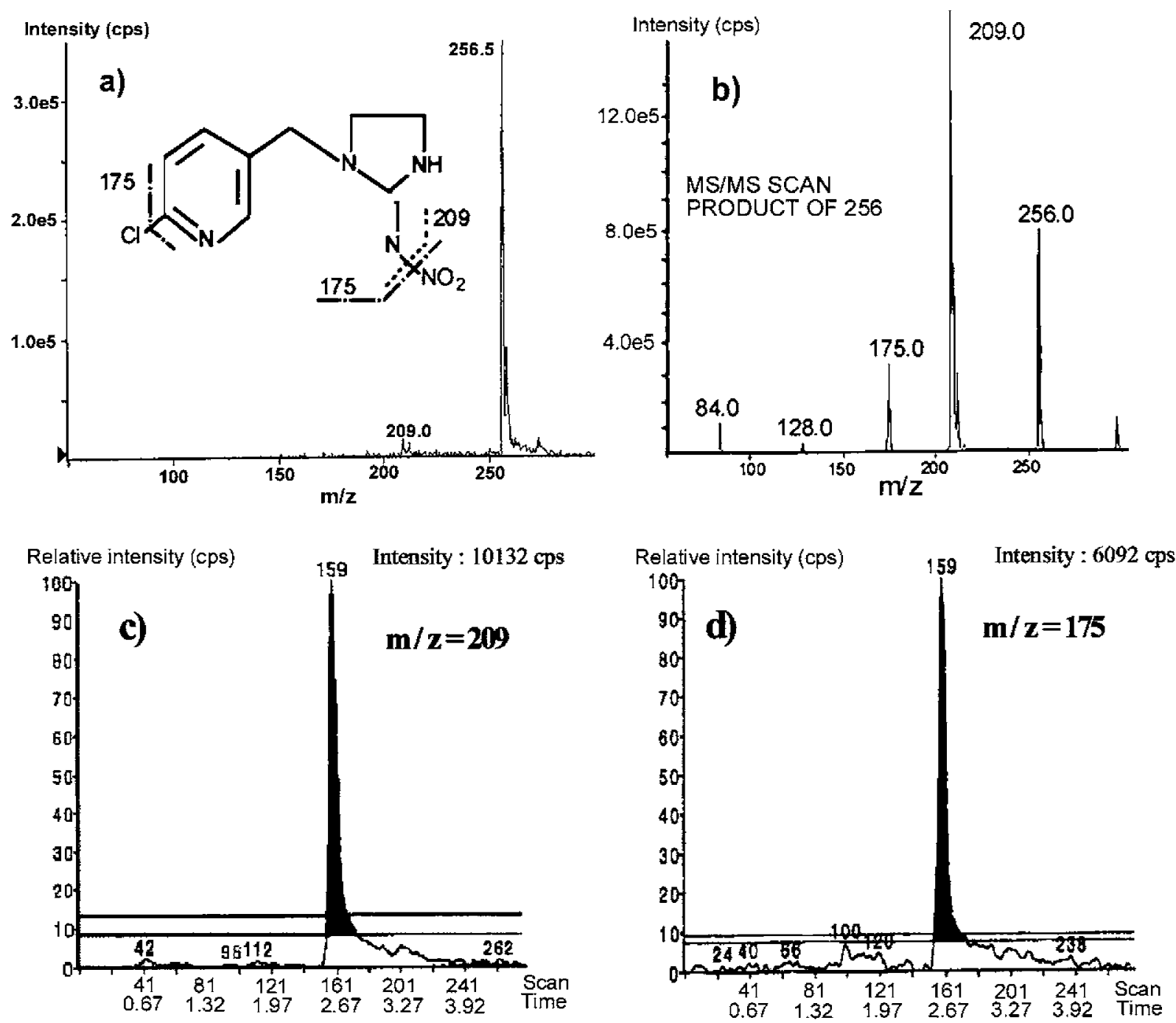

Figure 1. Detection of imidacloprid by mass spectrometry. (a) Mass spectra of imidacloprid corresponding to $[\mathrm{M}+\mathrm{H}]^{+}$with its ${ }^{35} \mathrm{Cl}$ and ${ }^{37} \mathrm{Cl}$ signals. The formula of imidacloprid is inset with a diagram showing the locations of fragmentations for the following tandem mass spectrometry. (b) MS/MS spectra of the $\mathrm{m} / z=256$ parent ion $\left({ }^{35} \mathrm{Cl}\right)$, exhibiting the product ions of imidacloprid at $\mathrm{m} / \mathrm{z}=209$ and at $\mathrm{m} / \mathrm{z}=175$. Two chromatograms of a soil sample (spiked before extraction with imidacloprid at $1 \mu \mathrm{g} / \mathrm{kg}$ ) are shown in (c) at $\mathrm{m} / z=209$ and in (d) at $\mathrm{m} / z=175$. The relative intensity scales correspond to $100 \%$ of the peak height.

was transferred to conical tubes. Additionally, the flask was rinsed twice with $20 \mathrm{~mL}$ of dichloromethane, and this solution was added to the conical tubes. The organic phase (the lower phase) was extracted and evaporated under a $\mathrm{N}_{2}$ flow. The oily residue was diluted with $2 \mathrm{~mL}$ of hexane and treated ultrasonically for $5 \mathrm{~min}$. One milliliter of $\mathrm{ACN} / \mathrm{H}_{2} \mathrm{O}$ (50/50) was added to the residue, and the resultant mixture was centrifuged ( $4000 \mathrm{rpm}$ ) for $5 \mathrm{~min}$. The upper phase was pipeted, transferred into 1.5-mL Eppendorf tubes, and centrifuged (1200 rpm) for $5 \mathrm{~min}$. A $100-\mu \mathrm{L}$ aliquot of the upper phase was sampled and added to $10 \mu \mathrm{L}$ of antipyrine ( 2 $\mathrm{ng} / \mathrm{mL})$ in $\mathrm{ACN} / \mathrm{H}_{2} \mathrm{O}(50 / 50)$. A total of $25 \mu \mathrm{L}$ was injected in HPLC.

(4) Standards Solutions, Calibrations Solutions, and Quality Control Samples. A typical run consisted of unknown samples included within series of injections of known material in order to check retention times (RT) and intensities of signals. Pure product samples were prepared with $\mathrm{ACN} / \mathrm{H}_{2} \mathrm{O}(50 / 50)$ at $10 \mu \mathrm{g} /$ $\mathrm{kg}$. Blank samples were obtained from the extraction of each blank matrix. Six calibration samples were prepared by spiking blank extracts with standard solutions. Fortification levels were $0.5,1$, $5,10,15$, and $20 \mu \mathrm{g} / \mathrm{kg}$. Quality control samples were also used to test the reproducibility within a run. They were prepared, for each matrix, from blanks spiked with imidacloprid before extraction. In this case, fortification levels were 2 and $5 \mu \mathrm{g} / \mathrm{kg}$. Other blank samples, supplemented at 1,10 , and $18 \mu \mathrm{g} / \mathrm{kg}$ and then extracted, were also used in order to test the repeatability for each matrix. Thus, a typical run for analyzing 10 unknown samples had at least 26 injections. The 16 additional samples were: the pure product, the eluting solution, the blank matrix without the external standard, the blank matrix, 8 calibration samples for quantification (the extreme levels being repeated twice), and 4 quality control samples ( 2 levels repeated twice).

Instrumentation. (1) LC/ APCI-MS/ MS Instrument. The Perkin-Elmer system (Framingham, USA) consisted of a LC pump and an injector of the Perkin-Elmer Series 200 and a mass spectrometer (Perkin-Elmer Sciex API 365) with an atmospheric source. The system was equipped with a binary solvent pump, an autosampler, and a MS system coupled with an analytical work 
Table 1. Ions Monitored under the MRM and SIM Mode by LC/MS/MS ${ }^{a}$

\begin{tabular}{|c|c|c|c|c|}
\hline \multirow[b]{2}{*}{ compound } & \multirow{2}{*}{$\begin{array}{c}\text { molecular } \\
\text { mass }(\mathrm{g} / \mathrm{mol})\end{array}$} & \multirow{2}{*}{$\begin{array}{l}\text { precursor } \\
\text { ion }^{b}(m / z)\end{array}$} & \multicolumn{2}{|c|}{$\begin{array}{c}\text { mass transition } \\
(m / z \rightarrow m / z)\end{array}$} \\
\hline & & & quantification & confirmation \\
\hline imidacloprid & 255.7 & 256.0 & $256.0 \rightarrow 209.0$ & $256.0 \rightarrow 175.0$ \\
\hline antipyrine & 188.2 & 189.0 & $189.0 \rightarrow 56.0$ & \\
\hline
\end{tabular}

${ }^{a}$ Imidacloprid (precursor ion at $\mathrm{m} / z=256.0$ ) was quantified with the $\mathrm{m} / z=209.0$ product ion. The data were confirmed with the ratio of the $\mathrm{m} / z=175.0$ to the $\mathrm{m} / z=209.0$ ion signals. Antipyrine (precursor ion at $\mathrm{m} / z=189.0$ ) was used as the external standard and was quantified with its $m / z=56.0$ product ion. ${ }^{b}$ Positive ionization mode.

station. The MS system was constituted of a standard atmo sphericpressure ionization source configured as APCI. The LC system was fitted with C8 BDS Hypersil $(4.6 \times 150 \mathrm{~mm})$ for the analysis of soils. For the analysis of plants and pollens, the LC system was fitted with a $\mathrm{C}_{18}$ Supelcosil $\mathrm{ABZ}+(150 \mathrm{~mm} \times 4.6 \mathrm{~mm})$ (Supelco Park, PA).

(2) LC Conditions. Separations were carried out at room temperature $\left(20{ }^{\circ} \mathrm{C}\right)$. A $25-\mu \mathrm{L}$ aliquot was injected for soils and pollens into the LC/ MS/ MS system. For plants, the injected volume was $20 \mu \mathrm{L}$. The mobile phase consisted of a mixture of ACN/ $\mathrm{H}_{2} \mathrm{O}(40 / 60)$ and $0.2 \%$ acetic acid. The separation was optimized for each matrix and the flow rate was set at $1 \mathrm{~mL} / \mathrm{min}$ for plants and $0.9 \mathrm{~mL} / \mathrm{min}$ for soils and pollens, for $6 \mathrm{~min}$. Prior to entering the source of the mass spectrometer, the LC column effluent was not splitted.

(3) APCI-MS/ MS Conditions. The APCI-MS interface was operated in the positive mode under the following conditions: 400 ${ }^{\circ} \mathrm{C}$ for gas temperature in the nebulizer, $20.0 \mathrm{~V}$ for the declustering potential, and $15 \mathrm{eV}$ for the collision-induced dissociation. Nebulizing gas (compressed air) pressure was $4 \mathrm{bar}$, and the corona current was $3.0 \mu \mathrm{A}$. The collision gas was $\mathrm{N}_{2}$. The electron multiplier voltage was $2 \mathrm{kV}$. The dwelling time was $200 \mathrm{~ms}$. Fullscan LC/ MS chromatograms were obtained by scanning from $\mathrm{m} / z$ $=50$ to $\mathrm{m} / z=800$ (Figure 1a). Mass calibration was done with polypropylene glycol. Selected-ion monitoring (SIM) of the most abundant ion was used for quantification. The detector of the mass spectrometer was tuned for the maximum sensitivity of the parent ion at $m / z=256 \pm 0.5$ and of the product ions at $m / z=209$ and at $\mathrm{m} / z=175$ (Figure 1b). The specificity was obtained by following these two specific fragmentations of imidacloprid. The first fragment, at $m / z=209$, is due to the loss of $\mathrm{NO}_{2}$. The second fragment, at $m / z=175$, is due to the losses of both $\mathrm{NO}_{2}$ and ${ }^{35} \mathrm{Cl}$ (Table 1, Figure 1c and d).

\section{RESULTS AND DISCUSSION}

Validation. One of the major difficulties was to keep both good selectivity levels and high recovery rates (see below). Then specificity is given by the chromatographic separation according to the LC conditions. In our conditions, RT was typically $2.4 \mathrm{~min}$ for the plant samples and $2.8 \mathrm{~min}$ for both the pollen and soil samples. Within a run (including the pure product, calibration samples, control samples, and unknown samples), RT was constant with a relative standard deviation never exceeding $2.5 \%$ The specificity was further assured by following the two characteristic fragmentations of imidacloprid. The chromatograms of the selected product ions are clearly defined with a high $\mathrm{S} / \mathrm{N}$ ratio. From multiple reaction monitoring (MRM) experiments, the ratio

\begin{tabular}{|c|c|c|c|c|c|c|}
\hline matrix & $\begin{array}{c}\text { no } \\
\text { calibrtn }\end{array}$ & $\begin{array}{l}\text { corr } \\
\text { coeff }\end{array}$ & $\begin{array}{l}\text { intercept } \\
(\mu \mathrm{g} / \mathrm{kg})\end{array}$ & $\begin{array}{l}\text { intercept } \\
\text { std dev }\end{array}$ & slope & $\begin{array}{l}\text { slope } \\
\text { std dev }\end{array}$ \\
\hline \multirow[t]{3}{*}{ soils } & 1 & 0.9929 & -0.663 & 0.723 & 1.0895 & 0.0654 \\
\hline & 2 & 0.9983 & -0.306 & 0.346 & 1.0375 & 0.0309 \\
\hline & 3 & 0.9995 & 0.112 & 0.183 & 0.9871 & 0.0163 \\
\hline \multirow[t]{5}{*}{ plants } & 1 & 0.9999 & -0.023 & 0.076 & 1.0025 & 0.0068 \\
\hline & 2 & 0.9992 & 0.205 & 0.218 & 0.9774 & 0.0194 \\
\hline & 3 & 0.9982 & -0.049 & 0.420 & 1.0073 & 0.0348 \\
\hline & 4 & 0.9995 & 0.079 & 0.215 & 0.9928 & 0.0178 \\
\hline & 5 & 0.9926 & 0.114 & 0.682 & 0.9958 & 0.0609 \\
\hline \multirow[t]{4}{*}{ pollens } & 1 & 0.9989 & 0.182 & 0.258 & 0.9805 & 0.0231 \\
\hline & 2 & 0.9973 & 0.124 & 0.409 & 0.9904 & 0.0366 \\
\hline & 3 & 0.9926 & 0.300 & 0.660 & 0.9701 & 0.0589 \\
\hline & 4 & 0.9985 & 0.137 & 0.293 & 0.9868 & 0.0263 \\
\hline
\end{tabular}

${ }^{a}$ These data were used to establish the linearity with a confidence level of $99 \%$ (Student's and Fisher's tests).

of the product ion signals (175/209) gives an averaged value close to 0.45 . The latter value comes from the analysis of standards as well as from the analysis of each spiked matrix (soils, plants, flowers, pollens). When unknown samples were analyzed, the ratio did not vary by more than $20 \%$ for a given matrix, thus satisfying the corresponding quality criteria. Another ratio, using the $\left[{ }^{35} \mathrm{Cl}\right]-$ and the $\left[{ }^{37} \mathrm{Cl}\right]$-imidacloprid signals, was also checked as a supplementary criterion of specificity. As mentioned above, antipyrine was systematically used as an external standard in order to check the retention time and to correct the intensity of signals.

Calibration graphs were plotted using at least six calibration samples from 0.5 to $20 \mu \mathrm{g} / \mathrm{kg}$. The graphs plotted the ratio of the imidacloprid signal to the antipyrine signal versus the spiked levels. For each matrix, at least three calibrations were made. The calibration results, including statistics, are shown for each matrix in Table 2. For each calibration, the correlation coefficient was always better than 0.992 . Thus, the calibration statistics shown a very satisfactory linearity with a confidence level of $99 \%$ in the whole of the calibration range (from 0.5 to $20 \mu \mathrm{g} / \mathrm{kg}$ ). Note that statistical analysis was performed on the slope, the intercept, and the variance with the $t$ test and $F$ test (Statgraphics plus 5.1, Sigma Plus). Additionally, the reproducibility of the calibration graphs for several months gave variation coefficients (VC) of the slopes of $12.2 \%$ for soils, $24.5 \%$ for plants, and $20.7 \%$ for pollens.

For determination of both the LOD and the limit of quantification (LOQ), the noise was first measured from 10 injections of blanks for each matrix. Measurements were done at $\mathrm{m} / \mathrm{z}=175$, which corresponds to the less intense product ion of imidacloprid. The noise centered around the retention time of imidacloprid was then averaged. The LOD was determined as the level for which 
Table 3. Repeatability $(n=6)$ and Recovery Rates $(R)$ for the Analysis of Imidacloprid in Soils, in Plants, and in Pollens, at Three Fortification Levels $(1,10$, and 18 $\mu \mathrm{g} / \mathrm{kg}$ )

\begin{tabular}{rrrrrrr} 
& \multicolumn{3}{c}{ amount $(\mu \mathrm{g} / \mathrm{kg})$} & & & \\
\cline { 2 - 3 } matrix & added & $\begin{array}{c}\text { found } \\
\text { (av, } n=6)\end{array}$ & std dev & VC $(\%)$ & $R(\%)$ \\
soils & 1 & 0.77 & 0.038 & 4.9 & 77.1 \\
& 10 & 9.48 & 1.20 & 12.7 & 94.8 \\
plants & 18 & 16.3 & 1.11 & 6.8 & 90.6 \\
& 1 & 0.85 & 0.078 & 9.2 & 84.6 \\
& 10 & 7.57 & 0.649 & 8.6 & 75.7 \\
pollens & 18 & 13.7 & 0.68 & 5.0 & 75.9 \\
& 1 & 0.85 & 0.045 & 5.3 & 84.9 \\
& 10 & 8.05 & 0.36 & 4.5 & 80.5 \\
& 18 & 14.00 & 1.57 & 11.2 & 78.0 \\
\hline
\end{tabular}

Table 4. Reproducibility and Recovery Rates $(R)$ of $n$ Analyses of Imidacloprid in Soils, in Plants, and in Pollens, at Two Fortification Levels (2 and $5 \mu \mathrm{g} / \mathrm{kg}$ )

\begin{tabular}{lcccccc} 
matrix & $\begin{array}{c}\text { amt added } \\
(\mu \mathrm{g} / \mathrm{kg})\end{array}$ & $\mathrm{n}$ & $\begin{array}{c}\text { amt found } \\
(\mu \mathrm{g} / \mathrm{kg})(\mathrm{av})\end{array}$ & std dev & $\mathrm{VC}(\%)$ & $R(\%)$ \\
soils & 2 & 10 & 1.7 & 0.18 & 10.7 & 85.2 \\
& 5 & 10 & 4.3 & 0.6 & 14.1 & 85.6 \\
plants & 2 & 20 & 1.6 & 0.28 & 17.5 & 78.3 \\
& 5 & 20 & 4.1 & 0.50 & 12.2 & 81.9 \\
pollens & 2 & 12 & 1.7 & 0.17 & 10.1 & 84.5 \\
& 5 & 11 & 4.1 & 0.61 & 15.0 & 80.9 \\
\hline
\end{tabular}

the $\mathrm{S} / \mathrm{N}$ ratio was greater than 3 . It was $0.1 \mu \mathrm{g} / \mathrm{kg}$ in soils and plants. The LOD was $0.3 \mu \mathrm{g} / \mathrm{kg}$ in pollens, which is very similar to results from statistical calculations. For instance, calculation from calibration curves using DIN 32645 gave a LOD between 0.26 and $0.32 \mu \mathrm{g} / \mathrm{kg}$ for pollens. The LOQ was first determined according to a $\mathrm{S} / \mathrm{N}$ ratio greater than 10 . It was then defined as the lowest quantified quantity with repeatability in agreement with all the quality criteria. The recovery rates $(R$, i.e., quantified amount/ real amount) were always between 70 and $110 \%$. The LOQ was $1 \mu \mathrm{g} / \mathrm{kg}$ for soils, plants, and pollens.

For each matrix, the repeatability was tested six times for three fortification levels of imidacloprid $(1,10$, and $18 \mu \mathrm{g} / \mathrm{kg})$. The blanks were spiked before extraction. Variation coefficients and recovery rates are depicted in Table 3 . Values of $\mathrm{VC}$ were always lower than $13 \%$ for the soils, lower than $10 \%$ for the plants, and lower than $12 \%$ for pollens. This is in agreement with the quality criteria. From a comparison with calibration samples, the recovery rates were (i) in the $77-95 \%$ range for soils, (ii) in the $75-85 \%$ range for plants, and (iii) in the 78-85\% range for pollens (Table 3 ). Note that the relative amounts of imidacloprid, given as results in the present paper, were not corrected by taking into account the recovery rates. Thus, these amounts can be considered as being minimized by about $5-20 \%$.

The reproducibility was determined for two fortification levels ( 2 and $5 \mu \mathrm{g} / \mathrm{kg}$ ) for each matrix. It was deduced from analysis of quality control samples spiked before extraction. The recovery rates were also calculated. They range between 78 and $86 \%$ (Table 4). The variation coefficients were lower than $18 \%$. Finally, the method respects the criteria (retention time, signal-to-noise ratio, ratio between the products ions, repeatability, reproducibility) from
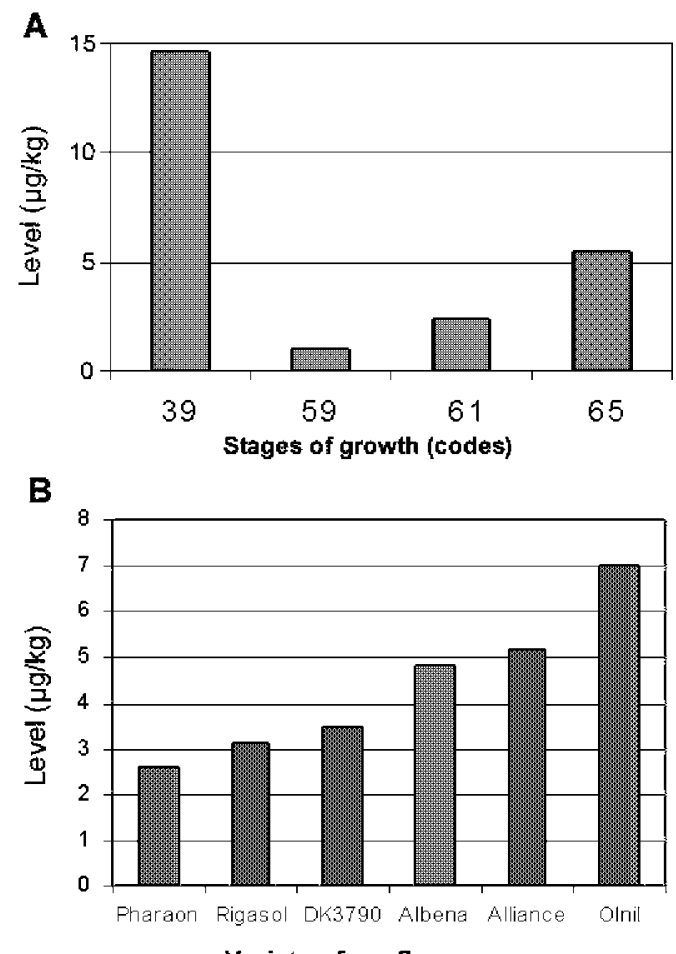

Variety of sunflowers

Figure 2. (A) Levels of imidacloprid $(\mu \mathrm{g} / \mathrm{kg})$ in sunflower as a function of the growing stages. These data correspond to averaged values from five varieties of sunflower growing in the same area. At stage 39, the bud is growing away from leaves. At stage 59, the capitule is formed and closed; flowers can be seen across the bracts. Stage 61 corresponds to the beginning of flowering. Full flowering occurs at stage $65 . .^{24}$ The imidacloprid level was averaged (i) in leaves and stems at stage 39 and (ii) in capitules at stages 59, 61, and 65 . As expected, the levels of imidacloprid in sunflower sharply decrease up to stage 59. However, from this stage onward, all varieties exhibit an increase of the imidacloprid content in capitules. (B) Levels of imidacloprid $(\mu \mathrm{g} / \mathrm{kg})$ in the capitules of sunflower at stage 59 as a function of the variety of sunflower. All the sunflowers were grown under the same experimental conditions in another area than for (A).

the directive 96/ 23/ EC, which is especially designed for banned substances.

Applications of the Method. We report data from the analysis of 74 samples of soils, 194 samples of plants (including flowers), and 64 samples of pollens. A total of 7 soils, 17 plants, and 11 pollens were sampled from organically farmed areas and served for validation of the method. No signal of imidacloprid was detected, and no interference occurs in these samples. These results show the absence of imidacloprid when the field has never been treated with imidacloprid. Additionally, they confirm that there is no contamination during sampling, storage, or analytical procedures.

(1) Soils. Analyses were performed from soils with various compositions (clayey, alluvial, chalky) so our results reflect a global and heterogeneous situation in France. When the field was treated with imidacloprid (seed dressing), imidacloprid is detected unambiguously in the soils at the end of the cultivation. The mean value is $12 \mu \mathrm{g} / \mathrm{kg}$ over the set of treated soils. The sensitivity of the method is such that the amount of imidacloprid in soils can be investigated in the microgram per kilogram range. Thus, the fate of imidacloprid in soils, 1 or 2 years after treatment, is now accessible. Here, the results from 33 soils, which were planted 

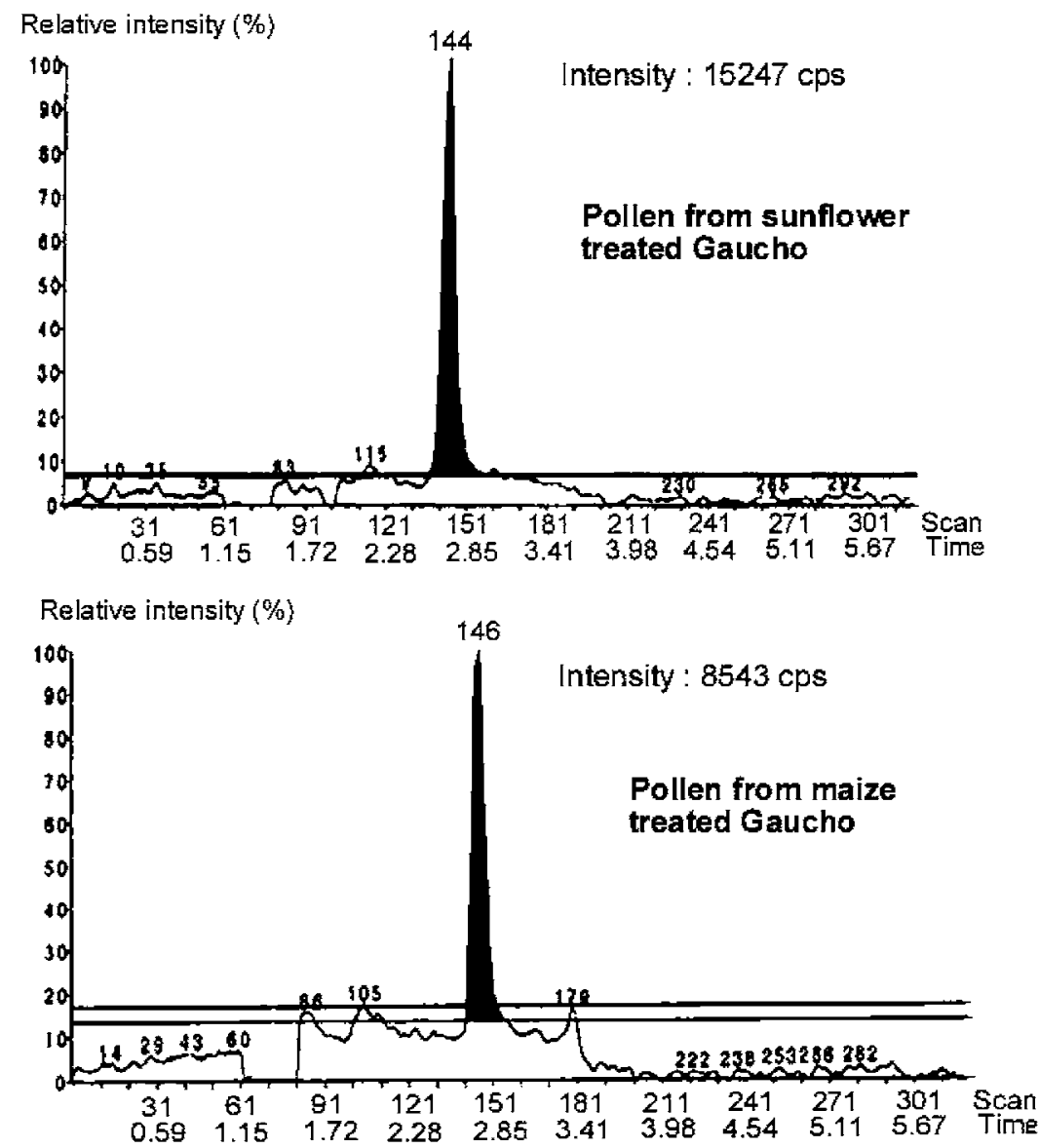

Figure 3. Typical chromatograms of pollen (detection at $\mathrm{m} / z=209$ ). (A) Pollen from sunflower treated with the Gaucho seed dressing (1.7 $\mu \mathrm{g} / \mathrm{kg}$ ). (B) Pollen from maize treated with the Gaucho seed dressing $(1.4 \mu \mathrm{g} / \mathrm{kg})$. The relative intensity scale corresponds to $100 \%$ of the peak height, whereas the amounts of imidacloprid were deduced from peak integration according to the calibration of each run. Analytical data satisfied the criteria reported in the validation section.

with treated seed 1 or 2 years before the sampling, were divided in different classes according to the residual concentration of imidacloprid. Only $3 \%$ of such soils did not have imidacloprid $(<0.1$ $\mu \mathrm{g} / \mathrm{kg}$ ), whereas $19 \%$ of these soils gave values between 0.1 and $1 \mu \mathrm{g} / \mathrm{kg}$. As a matter of fact, $78 \%$ of untreated soils still contain more than $1 \mu \mathrm{g} / \mathrm{kg}$ imidacloprid with an average value of $6 \mu \mathrm{g} /$ $\mathrm{kg}$. These results confirm the long persistence of imidacloprid in soils. Note that, as shown below, such a persistence in soils is the origin of the contamination of the next crops, even if they are not treated by a imidacloprid seed dressing.

(2) Plants. The method is suited for the analysis of a great variety of plants. Among the various plants that contain imidacloprid from seed dressing or from contaminated soils, we analyzed maize, rape, wheat, and sunflower. The results show that all these plants can still contain imidacloprid during flowering. Sunflower was studied thoroughly because the Gaucho treatment was suspected of having harmful effects on bees during foraging. Despite the fact that the amount of imidacloprid in growing plants sharply decreases with time, our data show a new phenomenon arising from the formation of the capitule (the head part) of sunflower. Actually, contamination stops decreasing and, on the contrary, starts to increase (Figure 2A). The increase of imidacloprid concentration during flowering was observed for five varieties of sunflower. The final concentration in flowers clearly depends on the variety. During flowering, the ascent of imidaclo- prid in the capitule leads to a final amount of toxin in flowers which is in the range of $5-10 \mu \mathrm{g} / \mathrm{kg}$ (averaged values). The sensitivity of the method was further exploited to follow several varieties of sunflower and to measure the uptake of imidacloprid in untreated sunflowers. A first point is given in Figure $2 \mathrm{~B}$, where six varieties can be compared. At the first stage of flowering, imidacloprid already ranges from 2.5 (Pharaon) to $7 \mu \mathrm{g} / \mathrm{kg}$ (Olnil) in capitules. A second point comes from the study of untreated sunflowers growing in fields treated with the Gaucho formulation 1 year before. Here, untreated sunflowers are able to take up the residual imidacloprid in contaminated soils. Capitules contain an averaged value of $1.5 \mu \mathrm{g} / \mathrm{kg}$ of imidacloprid, during flowering.

(3) Pollens. Figure 3 shows typical chromatograms of pollen from sunflower and maize that were treated with the Gaucho seed dressing. Note that the method gives unambiguous signals even for amounts of imidacloprid near the limit of quantification (LOQ $=1 \mu \mathrm{g} / \mathrm{kg}$ ). A set of 24 pollens was sampled and analyzed from sunflowers treated the same year. The results of this study show that imidacloprid was not detected (LOD $=0.3 \mu \mathrm{g} / \mathrm{kg}$ ) in $17 \%$ of samples. A proportion of $25 \%$ of pollens was positive, with amounts of imidacloprid not exceeding $1 \mu \mathrm{g} / \mathrm{kg}$. However, $58 \%$ of pollens contained imidacloprid at levels from 1 to $11 \mu \mathrm{g} / \mathrm{kg}$, with a mean value of $3 \mu \mathrm{g} / \mathrm{kg}$. A preliminary study on maize was done by sampling five pollens from treated crops. One of these pollens did not contain imidacloprid whereas the other four gave 
amounts from 1 to $3 \mu \mathrm{g} / \mathrm{kg}$ (average $2 \mu \mathrm{g} / \mathrm{kg}$ ). Obviously, the number of samples remains insufficient to describe the fate of imidacloprid in maize pollens, but the contamination of these pollens can no longer be neglected.

\section{CONCLUSIONS}

A specific extraction method has been developed with high recovery rates to analyze imidacloprid in soils, in plants, in flowers, and in pollens. New extraction schemes coupled to LC/ APCI-MS/ MS led to a very sensitive method (LOD $=0.1 \mu \mathrm{g} / \mathrm{kg}, \mathrm{LOQ}=1$ $\mu \mathrm{g} / \mathrm{kg}$ ). The present method can be classified as a confirmatory method for the analysis of imidacloprid or its metabolites according to the directive 96/23/ EC designed for analysis of banned substances. ${ }^{25-29}$ Analyses are relatively fast and have a reasonable cost. This technique provides a valuable tool to evaluate the bioavailability of imidacloprid in the environment. It is complementary to techniques using ${ }^{14} \mathrm{C}$-labeled compounds, since samples are collected on a realistic scale. The method is also suitable for investigating the residual imidacloprid 1 or 2 years after the initial treatment.

Our data were acquired under Good Laboratory Practices and respected strict protocols. The results demonstrated that imidacloprid contaminates the head part of the sunflower during flowering. Actually, amounts of this toxin increase, from the capitule formation, to reach $\sim 10 \mu \mathrm{g} / \mathrm{kg}$ in flowers during the foraging activity of bees. Obviously, such an amount clearly

(25) Bonmatin, J.-M.; Moineau, I.; Lecoublet, S.; Colin, M. E.; Fléché, C.; Bengsch, E. R. Proceedings of the 30th congress of the French Group of Pesticides, Produits Phytosanitaires: Analyse, résidus, métabolites, ecotoxicologie, modes d'action; Couderchet, M., Transferts; Eullaffroy, P., Vernet, G., Eds.; Presses Universitaires de Reims: Reims, 2001; pp 175-181.

(26) Bonmatin, J.-M. Sciences $2002,2,42-46$.

(27) Bonmatin, J.-M.; Moineau, I.; Lecoublet, S.; Colin, M.-E.; Fléché, C.; Bengsch, E. R. Proceeding of the 3rd European Pesticide Residue Workshop; Central Science Laboratory Ed.; Pesticides in Food and drink; York, 2000; p 134.

(28) Bonmatin, J.-M.; Moineau, I.; Lecoublet, S.; Colin, M. E.; Fléché, C.; Bengsch, E. R. Rev. Fr. Apiculture $\mathbf{2 0 0 0}, 609,360-361$.

(29) Bonmatin, J.-M.; Moineau, I.; Colin, M. E.; Bengsch, E. R.; Lecoublet, S.; Fleché, C. Rapport de résultats 3 au Ministère de l'Agriculture et de la Pêche, Programmes 1999-2000 AFSSA-CNRS-INRA, 2000.

(30) Bonmatin, J.-M.; Moineau, I.; Charvet, R.; Colin, M. E.; Fleché, C.; Bengsch, E. R. Behaviour of imidacloprid in fields. Toxicity for honey bees. In Environmental Chemistry; Springer: New York, in press.

(31) Laurent, F.; Scalla, R. Rapport de synthèse au Ministère de l'Agriculture et de la Pêche, 3 Åme Programme Communautaire pour l'apiculture, 2000.

(32) Nauen, R.; Reckmann, U.; Armborst, S.; Stupp, H.; Elbert, A. Pestic. Sci. 1999, 55, 265-271. depends on several parameters such as sunflower variety and the dose of seed dressing. ${ }^{30}$ Pollens from treated sunflowers were found to be contaminated with imidacloprid amounts at a few micrograms per kilogram. The averaged value is $3 \mu \mathrm{g} / \mathrm{kg}$. This corroborates results from ${ }^{14} \mathrm{C}$ experiments for which a total residue content of $\sim 13 \mu \mathrm{g} / \mathrm{kg}$ was found. ${ }^{31}$ Furthermore, Schnuck et al. also reported $3.3 \mu \mathrm{g} / \mathrm{kg}$ in pollen and $1.9 \mu \mathrm{g} / \mathrm{kg}$ in nectar. ${ }^{10}$

Others results strongly suggest that both sunflower and maize should exhibit a similar behavior. Actually, maize flowers contain the toxin with values between 1 and $20 \mu \mathrm{g} / \mathrm{kg}$. Results for maize pollens are also in the range of a few micrograms per kilogram.

Data from the soils confirmed that small amounts of imidacloprid remain at the end of cultivation (at the averaged level of $12 \mu \mathrm{g} / \mathrm{kg}$ ). However, 1 year after the treatment, the averaged level of imidacloprid is still at $6 \mu \mathrm{g} / \mathrm{kg}$. This is consistent with laboratory experiments which reported that the half-life of imidacloprid in soils vary from 3 to 6 months. ${ }^{12}$ Such a long persistence is the origin of the imidacloprid uptake by untreated plants growing on previously treated fields.

Finally, the present method can be used to study the migration or penetration of imidacloprid in soils. It is also possible to depict the distribution of the toxin in roots, leaves, stems, flowers, and pollens. The method was adapted to analyze honeys (not shown) in which imidacloprid does not occur significantly. Other extensions have been done to investigate individually several metabolites of imidacloprid (urea, monohydroxy, guanidine, and olefin derivatives). ${ }^{26,32}$ Adaptation of the method to water, fruits, and vegetables can also be done very easily. First assays in apples and peaches, from trees treated with another formulation (Confidor), have already revealed high signals of imidacloprid.

The use of the Gaucho seed dressing on sunflower has been suspended in France from 1999, with regard to the potential risk for bees.

\section{ACKNOWLEDGMENT}

This research was done for the French Ministries of Agriculture and Environment, with the financial support of the 1221/ 97/ EC program. The authors thank J.-C. Tabet, M.-F. GrenierLoustalot, S. Lecoublet, V. Charrier, and F. Westall for their help. 